\title{
Differential Expression of ARPP-16 and ARPP-19, Two Highly Related CAMP-Regulated Phosphoproteins, One of Which Is Specifically Associated with Dopamine-Innervated Brain Regions
}

\author{
Jean-Antoine Girault, Atsuko Horiuchi, Eric L. Gustafson, Neal L. Rosen, and Paul Greengard \\ Laboratory of Molecular and Cellular Neuroscience, The Rockefeller University, New York, New York 10021
}

\begin{abstract}
ARPP-16 and ARPP-19 are 2 CAMP-regulated phosphoproteins of $M_{r}=16,000$ and 19,000 , respectively, which are identical except for the presence of 15 additional amino acids on the $\mathrm{NH}_{2}$-terminus of ARPP-19. The phosphorylation of these 2 proteins is regulated by CAMP and vasoactive intestinal peptide in reaggregate striatal cultures (Girault et al., 1988). Using immunoblots and immunocytochemistry, we have compared the regional, subcellular, phylogenetic, and ontogenetic distributions of these 2 proteins. ARPP-19 was found in all vertebrate species studied and, at various levels, in all tissues of adult rat. ARPP. 19 was also present at high levels in malignant cell lines. During development ARPP-19 concentrations were highest in the embryo and decreased during the pre- and postnatal periods. In contrast, ARPP-16 was detected only in some specific neurons of the dopamine-innervated regions of the basal ganglia and the cerebral cortex, which are known to possess D1 dopamine receptors, in particular the striatonigral neurons. ARPP-16 is phylogenetically recent, being found only in birds and mammals, and appears late in ontogenesis, increasing during the postnatal period. These 2 proteins provide a unique model for studying the specificity of signal transduction and gene expression in dopaminoceptive neurons.
\end{abstract}

Many hormones and neurotransmitters exert their actions on target cells by raising the levels of cAMP, thereby activity cAMPdependent protein kinase. Activation of this kinase results in a variety of effects, including the alteration of the catalytic properties of enzymes, changes in the conductance of ion channels, and modification of the levels of expression of various genes (Nestler and Greengard, 1983; Nairn et al., 1985; Yamamoto et al., 1988). The effects induced by a given hormone or neurotransmitter acting through cAMP depend upon the cell type. This specificity is due to the selected expression of only a few of all the possible substrates for cAMP-dependent protein kinase

\footnotetext{
Received Sept. 1, 1989; revised Oct. 25, 1989; accepted Oct. 26, 1989.

We thank Drs. M. Bahler, J. Buxbaum, C. Gilbert, H. C. Hemmings, Jr., A. Hirano, Hui Quang, R. Llinas, R. Mira y Lopes, L. Ossowski, R. Nichols, F. Nottebohm, and F. Valtorta for the gift of some of the animal samples and cell lines used in this study. We are grateful to Dr. S. I. Walaas for help with the lesion experiments. The excellent technical assistance of Mrs. G. Bertuzzi was greatly appreciated. J.-A.G. was on leave of absence from Institut National de la Sante et de la Recherche Medicale (France). This work was supported by grant MH40899 from the United States Public Health Service and by Cooperative Agreement CR-813826 from the United States Environmental Protection Agency.

Correspondence should be addressed to Jean-Antoine Girault, INSERM U114,

Collcge de France, 11 Place Marcelin Bethelot, 75005 Paris, France.
}

Copyright (C) 1990 Society for Neuroscience $0270-6474 / 90 / 041124-10 \$ 02.00 / 0$ in any given cell type. In order to elucidate the mechanisms of cAMP-mediated signal transduction in a particular cell type, it is necessary to identify the substrates for cAMP-dependent protein kinase present in these cells. In nervous tissue, some substrates for cAMP-dependent protein kinase are specifically enriched in restricted neuronal populations (Walaas et al., 1983a, b). For instance, DARPP-32 (a dopamine- and cAMP-regulated phosphoprotein, $M_{\mathrm{r}}=32,000$ ), has been shown to be specifically enriched in dopaminoceptive cells, where it is thought to mediate some of the effects of dopamine acting on the D1 receptor (reviewed by Hemmings et al., 1987).

ARPP-16, a cAMP-regulated phosphoprotein of $M_{\mathrm{r}}=16,000$ (as determined by SDS-PAGE), enriched in the basal ganglia, has been purified from bovine caudate nucleus and its amino acid sequence has been determined (A. Horiuchi and P. Greengard, unpublished observations). ARPP-19 (cAMP-regulated phosphoprotein, $M_{\mathrm{r}}=19,000$ ) was identified because it copurified with ARPP-16, had identical phosphorylation sites, and cross-reacted with antibodies raised against ARPP-16 (ibid. and see below). The study of the cloned cDNAs for these 2 proteins revealed that the coding region of ARPP-16 is entirely included in the coding region of ARPP-19, suggesting that the mRNAs coding for these 2 proteins differ by alternative splicing and/or origin of transcription (ibid.). The sequence of the cDNAs predicts the existence of 16 additional amino acids at the $\mathrm{NH}_{2}$ terminus of ARPP-19. Direct study of the protein has shown that the $\mathrm{NH}_{2}$-terminal methionine is cleaved and that the next residue is probably blocked by an acetyl group, indicating that the ARPP-16 and ARPP-19 maturc proteins differ by only 15 $\mathrm{NH}_{2}$-terminal residues (ibid.). Although this peptide contains no consensus sequence for phosphorylation by cAMP-dependent protein kinase or protein kinase $C$, it is not known whether it undergoes other posttranslational modifications. These 2 highly related proteins are found in primary cultures of mouse caudate putamen, where their state of phosphorylation is regulated by cAMP and by vasoactive intestinal peptide (Girault et al., 1988).

To understand better the relationship between ARPP-16 and ARPP-19 we have compared their regional, subcellular, phylogenetic, and ontogenetic distributions. The results indicate that the expression of these 2 proteins differs dramatically. While ARPP-16 is expressed only in specific neuronal subpopulations of the dopamine-innervated regions of the brain and appears late both in phylogeny and ontogeny, ARPP-19 is expressed in virtually all cell types, appears early in phylogeny and ontogeny, and decreases during development. 


\section{Materials and Methods}

Materials. Male Sprague-Dawley rats and pregnant CDI mice were purchased from Charles River Laboratories. Canaries, frogs, and salamanders were gifts of Drs. Notebohm, Valtorta, and Hirano (The Rockefeller University), respectively. The other animals were obtained from commercial suppliers. ${ }^{25}$ I-iodo-protein A was from Dupont-New England Nuclear. Nitrocellulose membranes $(0.2 \mu \mathrm{m}$ pore size $)$ were from Schleicher and Schuell. Acrylamide was from Serva. Percoll was from Pharmacia. Nonidet P-40 was from Particle Data Laboratories Ltd. For measuring protein concentration, the reagent containing bicinchoninic acid (BCA) was from Pierce, and the reagent containing Coomassie brillant blue was from Bio-Rad. Reagents for the ABC procedure for immunocytochemistry were from Vector Labs. ARPP-16 and ARPP19 were purified to apparent homogeneity from bovine caudate nucleus (Horiuchi and Grcengard, unpublished obscrvations), and the protcin concentration was determined by quantitative amino acid analysis at the Rockefeller University Protein Sequencing Facility. Antiserum against ARPP-16 (G153) was prepared by subcutaneously injecting the protein coupled to thyroglobulin and mixed with Freund's complete adjuvant into female New Zealand rabbits. Contaminant antibodies against keratin were eliminated with a human keratin affinity column (Girault et al., 1989a). The IgG fraction, used in immunocytochemistry experiments, was prepared by affinity chromatography on a protein A-Sepharose column (Pharmacia). Rabbit antiserum specific for ARPP-19 (G249) was raised against a synthetic peptide corresponding to the 15 $\mathrm{NH}_{2}$-terminal residues present in ARPP-19, but not in ARPP-16, coupled to thyroglobulin. The serum was affinity-purified on a column of peptide coupled to activated $\mathrm{CH}$-sepharose 4B (Pharmacia).

Preparation of tissue extracts and immunolabeling. Animals from various species and at various ages were anesthetized with carbon dioxide and decapitated, and the organs of interest were dissected. Rat brain regions were dissected under a microscope, according to a rat brain atlas (Paxinos and Watson, 1986). Samples were frozen in dry ice and kept at $-70^{\circ} \mathrm{C}$ until analysis. Tissue pieces were homogenized by sonication in $2 \%(\mathrm{wt} / \mathrm{vol})$ boiling SDS and further maintained in a boiling water bath for $10 \mathrm{~min}$. Protein concentration was determined with a bicinchoninic-based assay (Smith et al., 1985), using bovine serum albumin as standard and equalized to $2.5 \mathrm{mg} / \mathrm{ml}$. One-fourth volume of stopsolution was added (final concentrations: SDS, $3 \%(\mathrm{wt} / \mathrm{vol})$; Tris-Cl, pH $6.8,62 \mathrm{mM} ; \beta$-mercaptoethanol, $0.3 \mathrm{M} ;$ glycerol, $5 \%$ (vol $/ \mathrm{vol})$, traces of pyronine $Y$ ), and samples were boiled for $2 \mathrm{~min}$. One hundred micrograms of protein from each sample were analyzed, together with standards of purificd ARPP-16 and ARPP-19, by clectrophorcsis on SDS-polyacrylamide gels (Laemmli, 1970) containing 13\% (wt/vol) polyacrylamide. Proteins were then transferred electrophoretically to nitrocellulose (Towbin et al., 1979). Immunoblotting, labeling of the antibodies with ${ }^{125}$ I-iodo-protein A, autoradiography, and quantification were performed as described (Girault et al., 1989b).

Lesioning of the striatonigral neurons. Lesioning of the striatonigral neurons was performed as described previously (Walaas and Greengard, $1984)$ with minor modifications. Male Sprague-Dawley rats (150-200 $\mathrm{gm})$, under pentobarbital anesthesia $(50-75 \mathrm{mg} / \mathrm{kg})$, were placed in a stereotactic apparatus (David Kopf). One microliter of $0.2 \mathrm{~m}$ quinolinic acid, adjusted to pH 7.4 with $\mathrm{NaOH}$, was infused into the rostral caudate putamen. Six days after the lesion, rats were sacrificed, and caudate putamen and substantia nigra from both sides of the brain were dissected. Tissue samples were frozen and ARPP-16 and ARPP-19 concentrations were determined by immunoblotting, as described above. As a measure of the efficacy of the lesions, the concentration of DARPP32 was determined in the same samples by immunoblotting (Girault et al., 1989b).

Immunocytochemistry. Five male Sprague-Dawley rats weighing 200$250 \mathrm{gm}$ were anesthetized with chloral hydrate $(400 \mathrm{mg} / \mathrm{kg})$ and perfused transcardially with $200 \mathrm{ml}$ of $0.9 \%$ (wt/vol) $\mathrm{NaCl}$, followed by $500 \mathrm{ml}$ of fixative $[4 \%(\mathrm{wt} / \mathrm{vol})$ paraformaldehyde in phosphate buffer $(0.1 \mathrm{~m}$ sodium phosphate, $\mathrm{pH} 7.4$ )] cooled to $10^{\circ} \mathrm{C}$. The brains were postfixed $1 \mathrm{hr}$ in cold fixative and stored until sectioning at $4^{\circ} \mathrm{C}$ in $20 \%(\mathrm{wt} / \mathrm{vol})$ sucrose in phosphate buffer. Brains were sectioned serially in either the coronal or sagittal plane, and $30-$ to $50-\mu \mathrm{m}$-thick sections were collected in phosphate buffer. The sections were washed 3 times for 10 min each in PBS (10 mM sodium phosphate, $\mathrm{pH} 7.6,155 \mathrm{~mm} \mathrm{NaCl}$ ) and incubated for $10 \mathrm{~min}$ in $10 \%(\mathrm{vol} / \mathrm{vol})$ normal goat serum. Adjacent groups of sections were then incubated overnight at room temperature with rabbit antisera against ARPP-16 (IgG fraction) or ARPP-19 (affinity-purified). ARPP-16 and ARPP-19 antisera were used at dilutions of 1:5000-
$1: 10,000$ and $1: 100-1: 500$, respectively, in PBS containing $1.0 \%$ (vol/ vol) normal goat serum. The tissue was then processed for immunocytochemistry according to a modification of the avidin-biotin complex (ABC) method (Hsu et al., 1981). The sections were washed in 3 changes of PBS as described above for the primary antibodies and placed in the biotinylated goat anti-rabbit $\operatorname{IgG}(1: 200)$. Following a $1.5 \mathrm{hr}$ incubation at room temperature, the sections were washed again and placed in the avidin-biotin complex coupled to peroxidase, diluted 1:50, which had been mixed $1.5 \mathrm{hr}$ earlier. After a $1.5 \mathrm{hr}$ incubation in ABC, the sections were washed in PBS and the antibodies were visualized with $0.05 \%$ (wt/ vol) 3,3'-diaminobenzidine and $0.012 \%$ ( $\mathrm{vol} / \mathrm{vol}$ ) hydrogen peroxide, dissolved in PB. The sections were then washed for $30 \mathrm{~min}$ in phosphate buffer and mounted on gelatin-coated slides. The reaction product was intensified using $0.1 \%$ osmium tetroxide (wt/vol) in phosphate buffer, and the tissue was dehydrated in graded ethanols, cleared with xylene, and coverslipped with Permount.

Subcellular fractionation. Subcellular fractionation was carried out according to a published protocol (Anthony et al., 1988) with few modifications. Caudate putamens from 6-9 rats were dissected and homogenized at $4^{\circ} \mathrm{C}$ in $10 \mathrm{vol} /$ weight of ice-cold buffer $(0.32 \mathrm{M}$ sucrose, $5 \mathrm{~mm}$ HEPES, pH 7.4, 1 mM EDTA, $0.5 \mathrm{~mm}$ EGTA, $1 \mathrm{~mm} \beta$-mercaptoethanol, $20 \mu \mathrm{g} / \mathrm{ml}$ leupeptin, $4 \mu \mathrm{g} / \mathrm{ml}$ pepstatin A, $5000 \mathrm{IU} / \mathrm{ml}$ aprotinin, and 1 mM PMSF), with 20 strokes of a Teflon pestle in a Potter-Elvehjem type glass homogenizer. Two milliliters of the homogenate were centrifuged at $1100 \times g$ for $5 \mathrm{~min}$. The pellet was resuspended in $2 \mathrm{ml}$ of buffer and centrifuged again at $1100 \times g$ for $5 \mathrm{~min}$. The supernatants of these 2 centrifugations were pooled and centrifuged at $1100 \times g$ for $5 \mathrm{~min}$. This third centrifugation yielded a supernatant ( $\mathrm{S} 1)$ and a pellet; this pellet was pooled with the pellet of the second centrifugation and, after suspension in buffer and centrifugation at $1100 \times g$ for $5 \mathrm{~min}$, yielded a pellet corresponding to the crude nuclear fraction (P1).Sl was centrifuged at $17,300 \times g$ for 17 min yielding a supernatant (S2) and a pellet corresponding to the crude synaptosomal fraction (P2). S2 was centrifuged at $100,000 \times \mathrm{g}$ for $75 \mathrm{~min}$, yielding a supernatant ( $\mathrm{S} 3$, cytosol) and a pellet (P3, crude microsomal fraction). P2 was further fractionated on a discontinuous density gradient of isotonic Percollsucrose $(0-3-10-23 \%$, vol/vol) centrifuged at $32,500 \times g$ for $5 \mathrm{~min}$ (Dunkley et al., 1986). This centrifugation yielded fractions at each interface, which corresponded, from top to bottom, to light membranes, myelin, synaptosomes, and mitochondria. The particulate fractions were resuspended in $5 \mathrm{ml}$ of buffer, centrifuged at $27,000 \times \mathrm{g}$ for $15 \mathrm{~min}$, and finally resuspended in buffer with $1 \%$ (vol/vol) Nonidet P-40. The protein concentration was determined in each fraction after solubilization in $10 \mu$ l of $1 \mathrm{~N} \mathrm{NaOH}$, with the dye-binding method of Bradford (1976), using bovine serum albumin as standard. The concentrations of ARPP-16 and ARPP-19 were determined by immunoblotting as described above. As a monitor of the fractionation, 5 proteins of known subcellular localization (DARPP-32, synapsin I, synaptophysin, myelin basic protein, and glial fibrillary acidic protein) were also analyzed in the same samples by immunoblotting (data not shown).

In experiments carried out to study the extractability of ARPP-16 and ARPP-19, rat caudate putamens were homogenized as described above in buffer without sucrose. Two milliliters of the crude homogenate were centrifuged at $150,000 \times g$ for $30 \mathrm{~min}$. The pellet was resuspended in $2 \mathrm{ml}$ of buffer and centrifuged again at $150,000 \times g$ for 30 min. The pooled supernatants of these 2 centrifugations formed the soluble fraction. Equal amounts of the pellet from the second centrifugation were resuspended in buffer with no addition (control) or buffer containing either $612 \mathrm{mM} \mathrm{NaCl}$ or $0.1 \%$ or $1 \%(\mathrm{vol} / \mathrm{vol})$ Nonidet P-40. The samples were then centrifuged at $150,000 \times \mathrm{g}$ for $30 \mathrm{~min}$ in order to separate the solubilized proteins from the particulate fraction. The protein concentration of each fraction was determined and the levels of ARPP-16 and ARPP-19 were measured as described above.

\section{Results}

Regional distribution of $A R P P-16$ and ARPP-19 in rat tissues and in various cell lines

The polyclonal antiserum raised against purified bovine ARPP16 reacted equally well against ARPP-16 and ARPP-19. However, these 2 proteins were resolved by SDS-PAGE and could be analyzed by immunoblotting after transfer to nitrocellulose. The concentrations of ARPP- 16 and ARPP-19 in various tissues were determined by comparison with known amounts of the 2 
Table 1. Concentrations of ARPP-16 and ARPP-19 in various rat tissues

\begin{tabular}{|c|c|}
\hline Tissue & $\begin{array}{l}\text { ARPP-16 } \\
(\mathrm{pmol} / \mathrm{mg})\end{array}$ \\
\hline \multicolumn{2}{|l|}{ Caudate putamen } \\
\hline Anterior & $5.0 \pm 0.5$ \\
\hline Mediodorsal & $4.2 \pm 0.6$ \\
\hline Medioventral & $3.0 \pm 0.5$ \\
\hline Posterior & $2.3 \pm 0.5$ \\
\hline Nucleus accumbens & $1.2 \pm 0.2$ \\
\hline Olfactory tubercle & $1.7 \pm 0.6$ \\
\hline Amygdala & $0.8 \pm 0.3$ \\
\hline Globus pallidus & $1.6 \pm 0.6$ \\
\hline Substantia nigra & $1.1 \pm 0.5$ \\
\hline \multicolumn{2}{|l|}{ Cerebral cortex } \\
\hline Prefrontal & $1.9 \pm 0.5$ \\
\hline Frontal & $2.1 \pm 0.4$ \\
\hline Anterior cingulate & $0.9 \pm 0.2$ \\
\hline Posterior cingulate & $0.9 \pm 0.2$ \\
\hline Parietal & $1.5 \pm 0.4$ \\
\hline Occipital & $1.2 \pm 0.2$ \\
\hline Temporal & $0.9 \pm 0.1$ \\
\hline Hippocampus & $0.3 \pm 0.1$ \\
\hline Septum & $0.3 \pm 0.1$ \\
\hline Thalamus & $0.6 \pm 0.1$ \\
\hline Hypothalamus & $0.4 \pm 0.1$ \\
\hline Olfactory bulb & ND \\
\hline Superior colliculus & ND \\
\hline Inferior colliculus & ND \\
\hline Periaqueductal gray & $\mathrm{ND}$ \\
\hline Cerebellar cortex & $\mathrm{ND}$ \\
\hline Pons & ND \\
\hline Medulla & ND \\
\hline Spinal cord & ND \\
\hline
\end{tabular}

ARPP-19 (pmol/mg)

$1.8 \pm 0.2$

$1.6 \pm 0.4$

$1.6 \pm 0.2$

$1.1 \pm 0.1$

$1.0 \pm 0.2$

$1.3 \pm 0.3$

$1.5 \pm 0.3$

$1.0 \pm 0.1$

$1.3 \pm 0.2$

$1.4 \pm 0.2$

$1.5 \pm 0.1$

$1.2 \pm 0.3$

$1.3 \pm 0.2$

$1.2 \pm 0.2$

$1.3 \pm 0.3$

$1.1 \pm 0.2$

$1.2 \pm 0.1$

$1.4 \pm 0.2$

$1.6 \pm 0.2$

$1.4 \pm 0.2$

$1.1 \pm 0.1$

$1.3 \pm 0.1$

$1.3 \pm 0.2$

$1.0 \pm 0.1$

$0.9 \pm 0.1$

$1.9 \pm 0.5$

$1.2 \pm 0.3$

$1.3 \pm 0.2$
Table 1. Continued

ARPP-16 ARPP-19

Tissue $\quad(\mathrm{pmol} / \mathrm{mg}) \quad(\mathrm{pmol} / \mathrm{mg})$

Optic nerve

Sciatic nerve

Pineal

Anterior pituitary

Posterior pituitary

Choroid plexus

Skeletal muscle

Heart

Intestine

Aorta

Fat

Thymus

Thyroid

Liver

Spleen

Kidney

Adrenal

Pancreas

Testis

Lung

Salivary gland

Lymph node

$\begin{array}{ll}\text { ND } & 1.2 \pm 0.1 \\ \text { ND } & 0.5 \pm 0.1 \\ \text { ND } & 1.0 \pm 0.4 \\ \text { ND } & 0.9 \pm 0.2 \\ \text { ND } & 0.9 \pm 0.1 \\ \text { ND } & 0.8 \pm 0.1 \\ \text { ND } & 0.3 \pm 0.1 \\ \text { ND } & 0.2 \pm 0.1 \\ \text { ND } & 0.8 \pm 0.1 \\ \text { ND } & 0.2 \pm 0.1 \\ \text { ND } & 0.2 \pm 0.1 \\ \text { ND } & 1.3 \pm 0.2 \\ \text { ND } & 0.7 \pm 0.3 \\ \text { ND } & 0.3 \pm 0.1 \\ \text { ND } & 0.8 \pm 0.1 \\ \text { ND } & 0.5 \pm 0.1 \\ \text { ND } & 1.4+0.4 \\ \text { ND } & 3.9 \pm 1.2 \\ \text { ND } & 1.5 \pm 0.2 \\ \text { ND } & 0.8 \pm 0.1 \\ \text { ND } & 0.4 \pm 0.2 \\ \text { ND } & 1.6 \pm 0.3\end{array}$

Tissues from adult rats were dissected and homogenized in boiling SDS, as described under Matcrials and Methods. Equal amounts of protein $(100 \mu \mathrm{g})$ from each tissue were separated by SDS-PAGE and transferred to nitrocellulose. The amounts of ARPP- 16 and ARPP-19 in each sample were determined by immunoblotting and quantified by comparison with known amounts of purified bovine ARPP-16 and ARPP-19. Data correspond to the mean \pm SEM of 4 experiments in which the proteins were measured in duplicate or triplicate. In many brain regions and in all the peripheral organs, ARPP-16 was not detectable (ND) with the method used.

Since ARPP-19 was found in all peripheral organs and was high during early embryogenesis (see below), we examined cell lines derived from various human and animal tissues for the presence of ARPP-19 (Fig. 1). The cells studied derived from human histiocytic lymphoma (U937), hepatoma (Hep 3B), cervix carcinoma (HeLa), melanoma (Bowes), breast carcinoma (MCF 7), rat neuroblastoma-glioma hybrid (N18 TG2), pheochromocytoma (PC 12), pituitary tumors (GH3 and AtT 20), and chinese hamster ovary (CHO). While ARPP-16 was not detected in any of these cell lines, ARPP-19 was found in all of them at levels equal or greater than in normal tissues, ranging from 2 to $4.5 \mathrm{pmol} / \mathrm{mg}$ protein.

\section{Effects of chemical lesions of the caudate putamen on the levels of ARPP-16 and ARPP-19}

Since both ARPP-16 and ARPP-19 were found in the caudate putamen and in the substantia nigra, striatal lesions were performed with quinolinic acid to determine whether these 2 proteins were contained in the striatonigral neurons. Injection of this excitotoxin into a given brain region destroys the neuronal ccll bodics without damaging the fibers, terminals, and glial cells (Schwarcz et al., 1983). Quinolinic acid was injected unilaterally in the caudate putamen and the levels of ARPP-16 and ARPP. 19 were measured $6 \mathrm{~d}$ later in the caudate putamen and the in testis, thymus, and adrenal gland. The lowest levels were in muscle, heart, aorta, fat, and liver. 


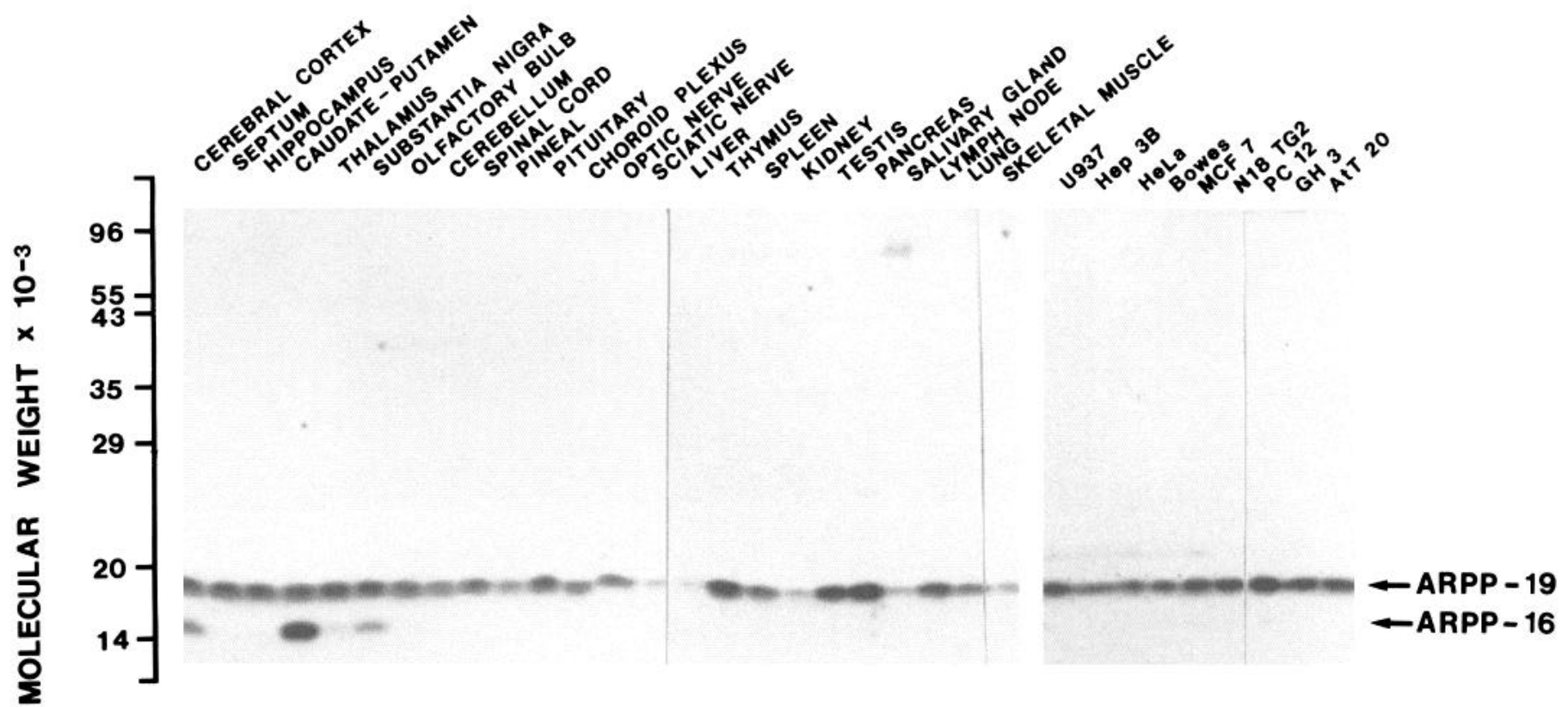

Figure 1. Distribution of ARPP-16 and ARPP-19 in tissues from adult rat and in various malignant cell lines. Tissues from adult rats and samples of various cell lines were homogenized in boiling SDS, as described under Materials and Methods. Equal amounts of protein (100 $\mu \mathrm{g})$ were separated by SDS-PAGE and transferred to nitrocellulose. ARPP-16 and ARPP-19 were immunolabeled with a serum against ARPP-16 which cross-reacted fully with ARPP-19 and visualized by ${ }^{125}$ I-iodo-protein A overlay and autoradiography.

substantia nigra ipsi- and contralateral to the lesion. The efficacy of the lesions was controlled by measuring the levels of DARPP32 , a known marker of the striatonigral neurons (Walaas and Greengard, 1984; Ouimet et al., 1984) in the same samples. The levels of DARPP-32 dropped in the caudate putamen and the substantia nigra ipsilateral to the lesion (decrease $>85 \%$, as compared with the control side), suggesting that most of the neurons in the caudate putamen were destroyed by the lesion. The decrease in the levels of ARPP-16 was also very pronounced, both in the caudate putamen $(-89 \%)$ and in the substantia nigra (-71\%; Fig. 2), showing an enrichment of ARPP16 in the striatonigral neurons. The decrease of ARPP-19 levels in the caudate putamen ( $-71 \%$, Fig. 2), following local injection of quinolinic acid, indicated that ARPP-19 is predominantly located in neurons and not in glial cells. Moreover, the concomitant decrease of ARPP-19 in the ipsilateral substantia nigra $(-41 \%$, Fig. 2$)$ demonstrated its presence in the striatonigral neurons.

\section{Study of the cellular localization of ARPP-16 and ARPP- 19 by immunocytochemistry}

The distribution of ARPP- 16 was studied in rat brain by immunocytochemistry using an antiserum (G1.53) against ARPP16 , which reacted equally well with ARPP-16 and ARPP-19 on immunoblots, as well as an antiserum (G249) raised against a synthetic peptide corresponding to the 15 amino acid $\mathrm{NH}_{2}-$ terminus specific for ARPP-19. The specificity of the immunolabeling with both sera was shown by the lack of staining with preimmune sera. Moreover, immunostaining with serum G153 was blocked by preincubation with purified bovine ARPP-16, and serum G249 was used after affinity purification on a peptide antigen affinity column. The results for each region were interpreted by taking into account 3 parameters: the intensity of the staining obtained with the antiserum against ARPP-16; the staining obtained with the specific antiserum against ARPP-19; and the relative abundance of ARPP-16 and ARPP-19 determined by immunoblotting.

Antibodies to ARPP-19 weakly labeled most of the neurons in the brain, although some neurons were somewhat more intensely stained. In contrast, the staining for ARPP-16 showed large variations in intensity among various brain regions (Fig. 3). In several areas which contained high levels of ARPP-16 on immunoblots, a very strong staining of some neurons was obrined with anti-ARPP-16 serum but not with the specific anti-

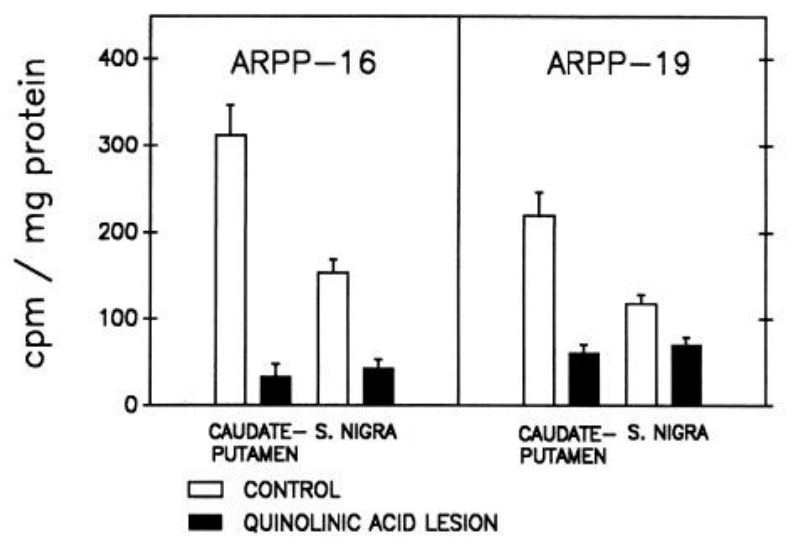

Figure 2. Effects of unilateral lesions of rat caudate putamen with quinolinic acid on the levels of ARPP-16 and ARPP-19. Six days after a unilateral lesion of the caudate putamen with quinolinic acid, the substantia nigra and the caudate putamen were dissected from both sides of the brain. ARPP-16 and ARPP- 19 were measured by immunoblotting, as described under Materials and Methods. Data correspond to means \pm SEM from 6 animals. All the differences between control and lesioned sides were statistically significant $(p<0.01)$ using 2-tailed, paired Student's $t$ test. 
Figure 3. Distribution of ARPP-16immunoreactive cell populations in rat brain. Photomicrograph of a rat brain sagittal section stained with antiserum against ARPP-16 and processed using the avidin-biotin complex method, as described under Materials and Methods. Micrographs were prepared by placing microscope slides in a photographic enlarger and producing negative images on photographic paper. Thus, the immunoreactivity appears white. The serum against ARPP-16 gave an intense immunoreactivity in the caudate putamen $(C P)$ and the substantia nigra, pars reticulata $(\mathrm{SNr})$.

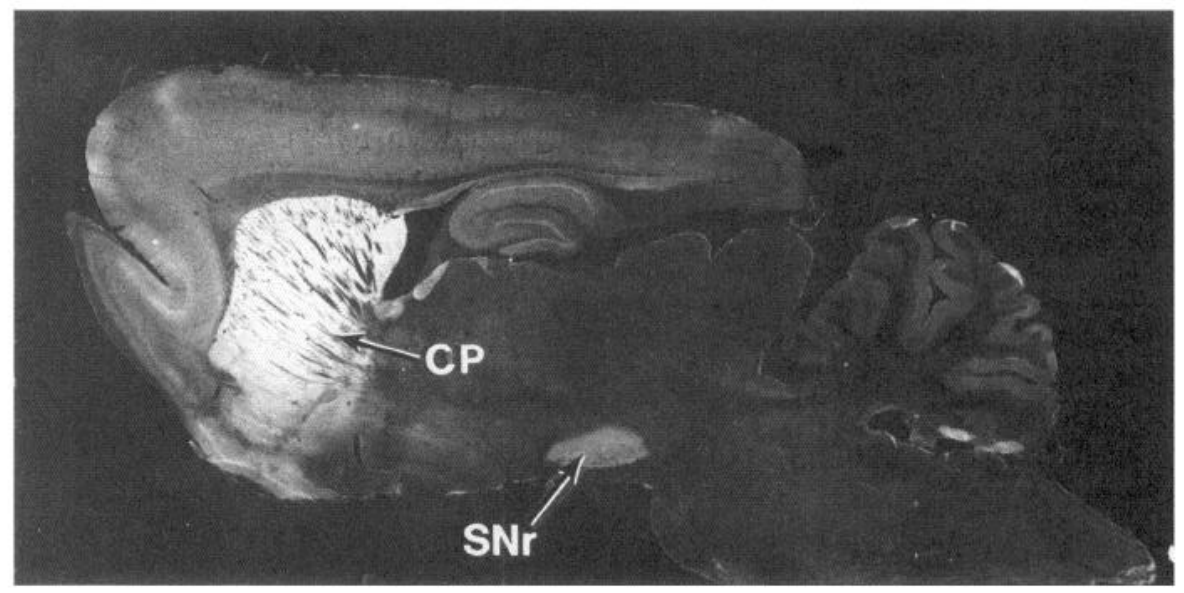

ARPP-19 serum. This was particularly the case for a large proportion of the medium-sized neurons of the caudate putamen, which had the most intensely immunostained perikarya and dendrites in the brain (Fig. $4, A, B$ ). In the caudate putamen, the anti-ARPP-19 antiserum gave a weak staining of the medium-sized neurons and a slightly stronger staining of large neurons (Fig. $4 C$ ). Therefore, the very strong immunoreactivity of medium-sized neurons observed with the serum against ARPP16 was most likely attributable to the presence of high concentrations of ARPP-16 in these cells. Neurons strongly labeled with the anti-ARPP-16 serum were also seen in the nucleus accumbens and the olfactory tubercle, while the bed nucleus of the stria terminalis and the central nucleus of the amygdala contained substantial populations of moderately labeled neurons. Dense plexus of axons immunoreactive with the antiARPP-16 serum, without immunolabeled perikarya, were visualized in all the major efferent terminal areas of the caudate putamen, including the globus pallidus, ventral pallidum, entopeduncular nucleus, and substantia nigra, pars reticulata (Figs. $3,4 D)$.

In some other areas in which immunoblots indicated the presence of both ARPP-16 and ARPP-19, a comparable staining was obtained with both antisera. These included moderately labeled neocortical neurons in layers II, III, V, and VI and hippocampal pyramidal cells which were weakly labeled, while their dendrites appeared to be more intensely immunoreactive. Finally, in some areas labeling was observed with both antisera, but ARPP-16 was not detected on immunoblots, suggesting that most, if not all of the immunoreactivity corresponded to ARPP19. This was the case in particular for the cerebellar Purkinje cells and their dendrites (Fig. 4, $E, F$ ).

\section{Subcellular distribution of ARPP-16 and ARPP-19 in rat caudate putamen}

The distribution of ARPP-16 and ARPP-19 was studied in various subcellular fractions prepared by homogenization of rat caudate putamen in isotonic buffer followed by differential cen- trifugation (Anthony et al., 1988). ARPP-16 was found predominantly in the cytosol $(40 \%$ of the total tissue content), and the rest was associated with various particulate fractions, especially the crude nuclear fraction (P1, 25\% of the total tissue content) (Fig. 5A). The results for ARPP-19 were similar, except that the amount of this protein found in the cytosol was higher than for ARPP-16 (54\% of the total tissue content).

In a second series of experiments, the extractability of ARPP16 and ARPP-19 was studied following homogenization in hypotonic buffer (Fig. $5 B$ ). In these conditions, only $52 \%$ of the total ARPP-16 was solubilized. ARPP-16 was extracted from the particulate fraction either with high salt $(63 \%)$ or with $1 \%$ ( $\mathrm{vol} / \mathrm{vol}$ ) Nonidet P-40 (75\%). ARPP-19 was more readily solubilized in hypotonic buffer (71\%) than ARPP-16 (Fig. 5B).

\section{Phylogenetic study of ARPP-16 and ARPP-19}

The presence of immunoreactive proteins with an apparent molecular weight on SDS-PAGE similar to ARPP-16 or ARPP-19 was investigated in samples of nervous tissue from various invertebrate and vertebrate species. No such immunoreactivity was observed in the invertebrate species studied, including Aplysia californica (Fig. 6), Drosophila melanogaster, and squid Loligo pealeii. On the other hand, an immunoreactive band of $M_{\mathrm{r}} \sim 19,000$ was found, with approximately the same intensity, in all the vertebrate species studied (Fig. 6). The immunoreactive protein in frog (Rana pipiens) had a slightly higher molecular weight. In contrast, ARPP-16 was observed only in mammals and in 1 of the 2 bird species studied (Fig. 6). ARPP-16 was found in canary (Serinus canarius), but not in pigeon $(\mathrm{Co}-$ lumba livia). An additional immunoreactive band $\left(M_{\mathrm{r}}=48,000\right)$ was observed reproducibly in 2 species of bony fishes, gold fish (Carassius auratus, Fig. 6) and carp (Cyprinus carpio, data not shown). The significance of this immunologically related protein in fish remains to be determined. In monkey, Macaca mulatta, a high-molecular-weight immunoreactive band was observed in both caudate nucleus and cerebral cortex (Fig. 6). This immunoreactive band may correspond to an artifactual aggrega-

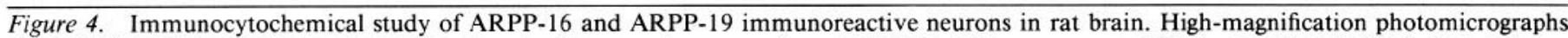

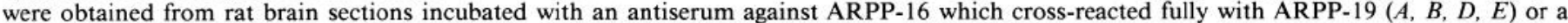

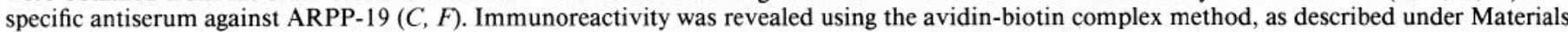

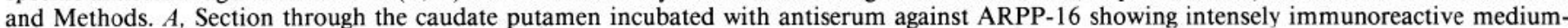



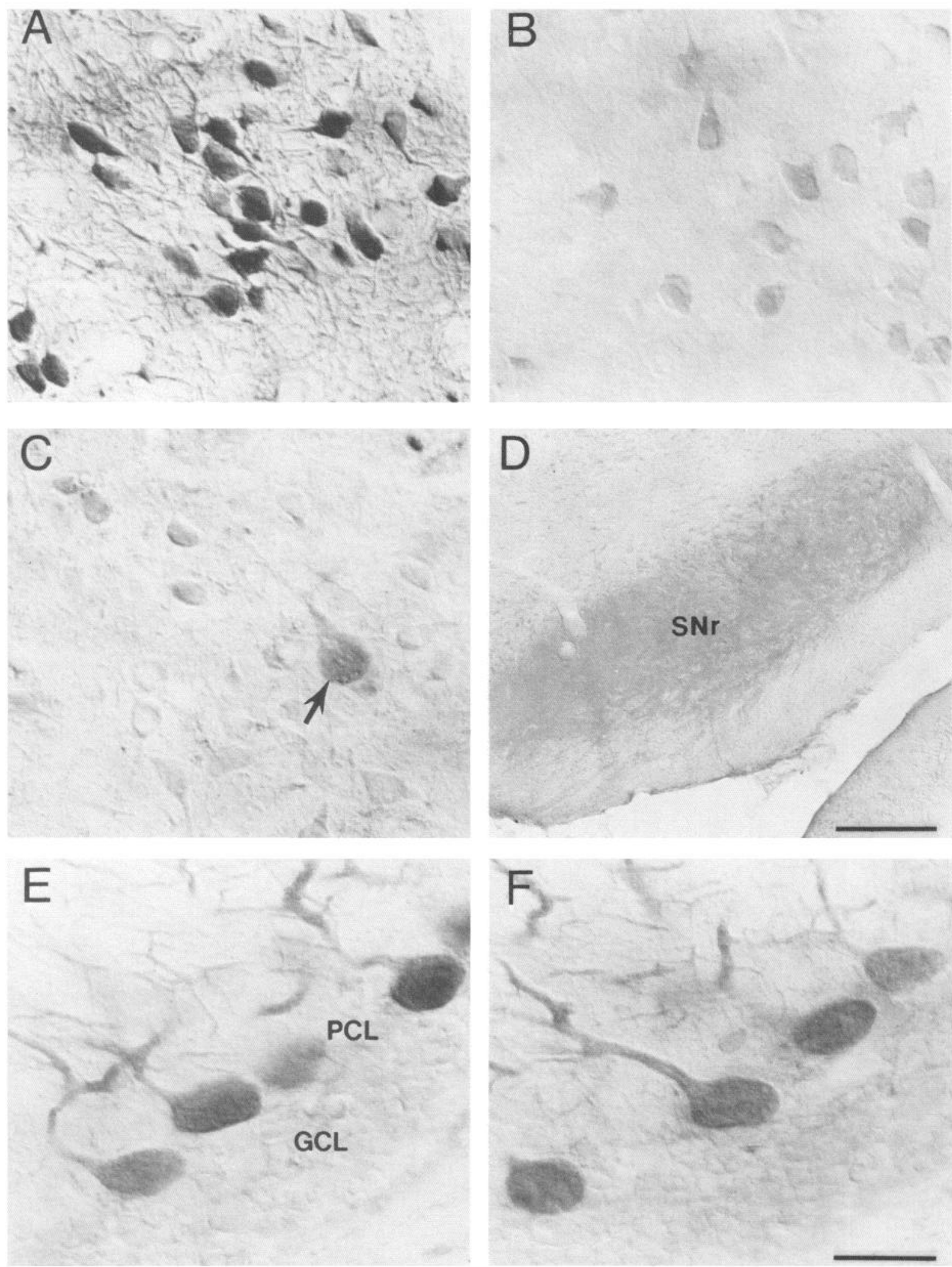

sized neurons. The neuropil is also immunoreactive. $B$, Adjacent section to that in $A$, demonstrating the marked reduction in labeling following preadsorption of the ARPP-16 antiserum with purified bovine ARPP-16. $C$, Section through the caudate putamen incubated with antiserum against ARPP-19. In addition to the low-intensity immunostaining of medium-sized neurons, the antiserum against ARPP-19 also labeled large neurons (arrow). $D$, In the substantia nigra, pars reticulata, antiserum against ARPP-16 labeled immunoreactive axons but no cell bodies. Scale bar, 300 $\mu \mathrm{m} . E$ and $F$, Photomicrographs of adjacent sagittal sections of cerebellum labeled with antisera against ARPP-16 $(E)$ or ARPP-19 $(F)$. Purkinje cells were stained with approximately the same intensity with both antisera and the immunoreactivity can be attributed to the presence of ARPP. 19 in these cells, since only ARPP-1 was detected on immunoblots from cerebellar cortex. $P C L$, Purkinje cell layer; $G C L$, granule cell layer. Scale bar in $F=30 \mu \mathrm{m}$ and applies to $A, B, C, E$, and $F$. 

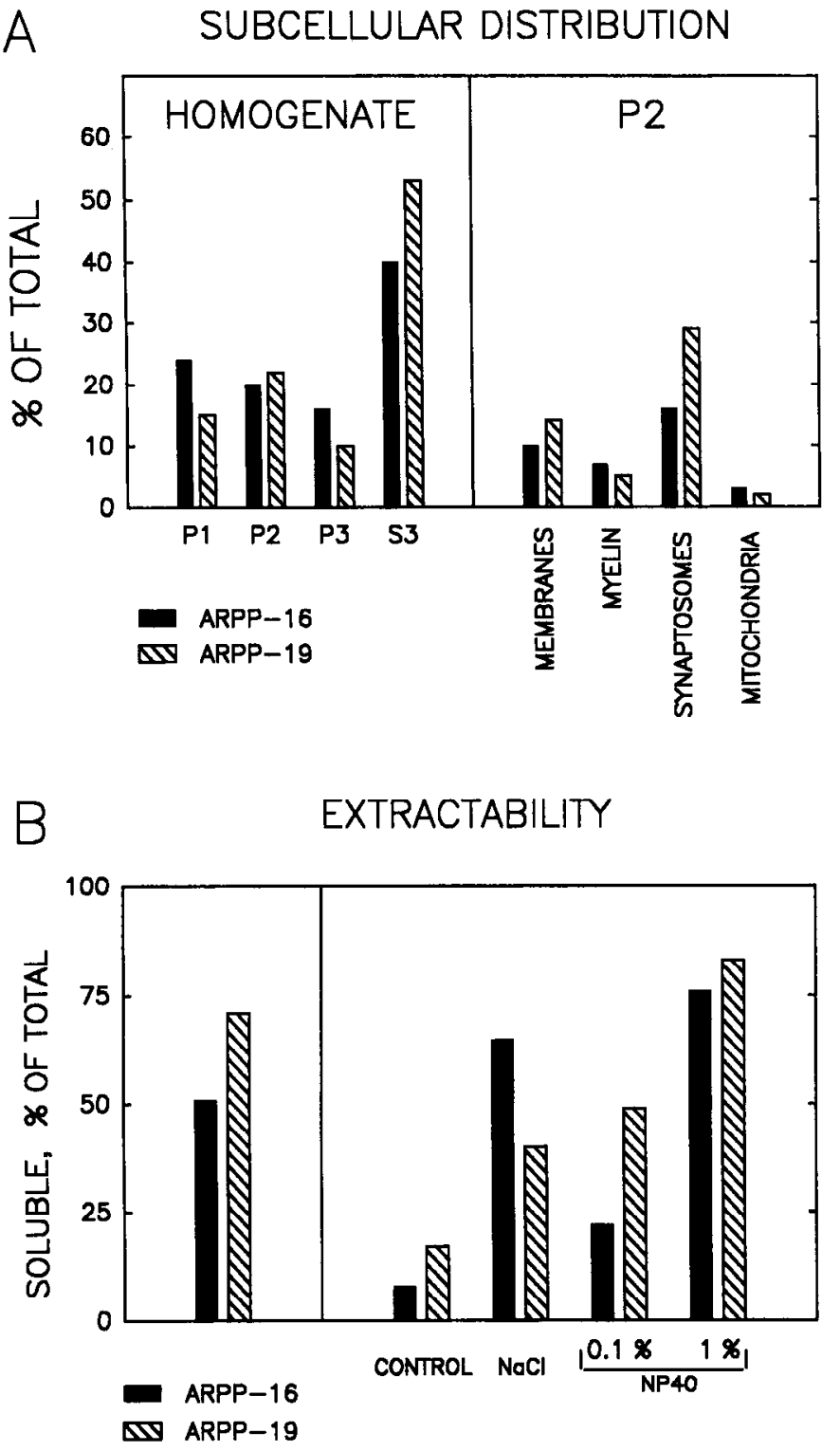

Figure 5. Subcellular distribution and extractability of ARPP-16 and ARPP-19 in rat caudate putamen. $A$ : Left, Rat caudate putamen was homogenized in isotonic buffer and fractionated by differential centrifugation as described under Materials and Methods. The fractions obtained corresponded to the crude nuclear pellet $(P l)$, the crude synaptosomal fraction $(P 2)$, the crude microsomal fraction $(P 3)$, and the cytosol (S3). Right, P2 was further fractionated into light membranes $(\mathrm{Mem}$ branes), myelin, synaptosomes, and mitochondria, using a discontinuous Percoll-sucrose gradient. The amount of ARPP-16 and ARPP-19 in each fraction was expressed as the percentage of the total amount contained in the homogenate (left panel) or in P2 (right panel). Data correspond to the mean of 2 independent experiments in which the proteins were measured in duplicate. $B:$ Left, Rat caudate putamen was homogenized in hypotonic buffer and the soluble and particulate fractions were separated by centrifugation, as indicated under Materials and Methods. Right, The particulate fraction was then reextracted into the same buffer without addition (Control) or in the presence of $\mathrm{NaCl}$ ( 625 $\mathrm{mm})$ or Nonidet P-40 [0.1 or $1 \%(\mathrm{vol} / \mathrm{vol})]$. ARPP-16 and ARPP-19 were measured in each pellet and supernatant by immunoblotting. The amount of extractable ARPP-16 and ARPP-19 is expressed as a percentage of the total (i.e., soluble + particulate). Data correspond to the mean of 2 independent experiments in which the proteins were measured in duplicate. tion of ARPP-19 since it was also observed in some samples of human tissue which had been stored frozen for long periods of time (data not shown) but was not found in samples of human cell lines (Fig. 1).

\section{Development of ARPP-16 and ARPP-19 in mouse}

The development of ARPP-16 and ARPP-19 was studied in various brain regions and in liver of mice from the embryonic day 16 to postnatal week 8 (Fig. 7). ARPP-16 appeared at the end of the first postnatal week in caudate putamen, cerebral cortex, and hippocampus. The levels increased until 8 weeks in the caudate putamen but reached a plateau at 3 weeks in the cortex. In contrast, the levels of ARPP-19 were maximum in the embryo and decreased progressively with development in all regions studied (Fig. 7). In liver, where ARPP-16 was not detected at any time, the levels of ARPP-19 were already lower than in brain before birth and decreased progressively with development.

\section{Discussion}

ARPP-16 and ARPP-19 are both substrates for cAMP-dependent protein kinase in intact cells (Girault et al., 1988) and are likely to mediate some of the effects of those neurotransmitters and hormones that increase cAMP levels in the cells in which they are located. The high degree of structural identity between ARPP-16 and ARPP-19 (Horiuchi and Greengard, unpublished observations) suggests that their function is, at least in part, similar. Despite the similarity between ARPP-16 and ARPP19 in terms of regulation and structure, the present study shows that the expression of these 2 proteins differs dramatically. ARPP19 was detected in all the tissues studied in the adult rat, the highest levels being found in pancreas, testis, brain, thymus, and adrenal gland. In brain, ARPP-19 was predominantly located in neurons, as indicated by its decrease in the caudate putamen following neuron-specific lesion with quinolinic acid and by the neuronal staining in immunocytochemistry. These results are in agreement with the higher levels of ARPP-19 in neuroglial reaggregate cultures from 5 different brain regions than in pure astroglial cultures (Girault et al., 1988).

A striking feature of ARPP-19 was its high abundance in embryonic tissue and its progressive decrease with development. A similar decrease with time in the levels of ARPP-19 has been observed in striatal cells in culture, concomitant with the progressive increase in the levels of synapsin I, a synaptic vesicle-associated protein, and ARPP-16 (Girault et al., 1988). The present study demonstrates that this decrease also occurs in vivo, regardless of whether the tissue expresses ARPP-16, indicating that the down-regulation of the expression of ARPP19 is independent of the appearance of ARPP-16 and does not correspond to a shift from one form to the other. This progressive decrease in the levels of ARPP-19 during development is analogous to that of proteins highly expressed during development such as GAP-43 (Jacobson et al., 1986) and contrasts sharply with the increase of markers of neuronal differentiation, such as synapsin I (Lohmann et al., 1978; Moore and Bernstein, 1989), DARPP-32 (Foster et al., 1987), and neurotransmitterassociated markers (Kessler, 1986; Bond et al., 1988).

ARPP-19 was also found at high levels in malignant cell lines, indicating that the levels of expression of ARPP-19 are higher in cells which are not fully differentiated and/or which are proliferating. The association between proliferation and the expression of ARPP-19 is not exclusive, however, since the highest 


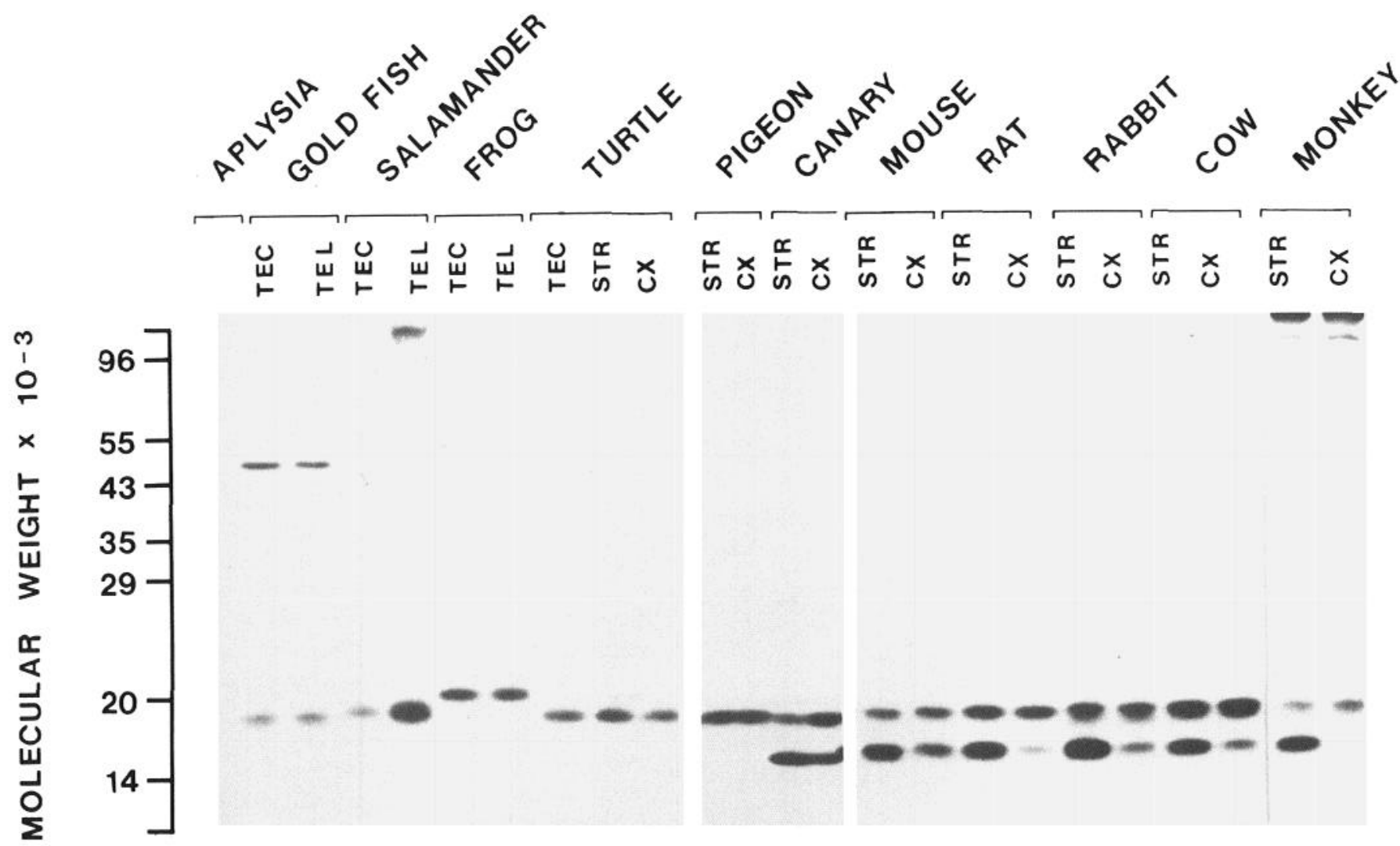

Figure 6. Distribution of ARPP-16 and ARPP-19 in nervous tissue from various species. Nervous tissue from various animals was dissected and homogenized in boiling SDS, as described under Materials and Methods. Equal amounts of protein (100 $\mu \mathrm{g})$ from each tissue were separated by SDS-PAGE and transferred to nitrocellulose. ARPP-16 and ARPP-19 were immunolabeled with a serum against ARPP-16 and visualized by ${ }^{125}$ Iiodo-protein A overlay and autoradiography. Tec, tectum; Tel, telencephalon; Str, paleostriatum in turtle and birds or caudate putamen in mammals; $C x$, frontal cerebral cortex.

levels of ARPP-19 in the adult were found in pancreas and brain, where few or no cell divisions take place. The existence of high levels of ARPP-19 in cell lines in which growth arrest and differentiation can be induced in vitro should allow the determination of the relationship between high levels of expression of ARPP-19 and cell proliferation.

In the phylogenetic survey, ARPP-19-like immunoreactivity was not detected in invertebrates but was found, with a similar intensity, in all vertebrate species studied, belonging to several classes (fishes, anoure and urodele amphibians, reptiles, birds, and mammals), demonstrating that ARPP-19 is highly conserved among vertebrates, at least in the region of the epitope recognized by the antiserum. Although the function of ARPP19 is not yet known, our results indicate that this protein is involved in ubiquitous processes in vertebrate cells.

In contrast with the ubiquitous nature of ARPP-19, ARPP16 was expressed in a very restricted set of neurons, mostly within the basal ganglia and the cerebral cortex. Immunocytochemistry and lesion experiments demonstrated that the highest levels of ARPP- 16 were contained in the medium-sized neurons of the caudate putamen, which project to the globus pallidus and the substantia nigra. These neurons, which belong to the medium-sized spiny type, are known to use GABA, substance $\mathrm{P}$, and enkephalins as neurotransmitters (reviewed in Graybiel and Ragsdale, 1983). Within the striatonigral neurons, ARPP16 was relatively concentrated in the caudate putamen (i.e., the region of cell bodies and dendrites), as compared with the globus pallidus and the substantia nigra (i.e., the region of nerve terminals). The relatively high concentration of ARPP-16 in the somatodendritic region suggests its association with a fixed component of this part of the neurons. Moreover, although both ARPP-16 and ARPP-19 were predominantly found in the cytosol, a significant proportion of the total ARPP-16 was associated with the particulate fraction, and this association was disrupted by high ionic strength. These observations raise the possibility that an interaction may exist between ARPP-16 and some component of the cytoskeleton, comparable to the interaction between microtubules and some microtubule-associated proteins which exhibit a preferential localization in specific regions of the neuron (Matus, 1988; Schoenfeld et al., 1989).

ARPP-16 did not appear to be exclusively expressed in neurons using a given type of neurotransmitter. On the other hand, the brain regions containing ARPP-16 matched closely those receiving a dense dopaminergic innervation (Bjorklund and Lindvall, 1984), and even more precisely with the distribution of D1 dopamine receptors (Boyson et al., 1986; Dawson et al., 1986; Dubois et al., 1986; Savasta et al., 1986). For instance, in the substantia nigra ARPP-16 was located exclusively in the striatonigral fibers, like the $\mathrm{D} 1$ receptors, while the $\mathrm{D} 2$ receptor is found on local neurons (Quik et al., 1979). This localization is comparable to the distribution of 2 other cAMP-regulated phosphoproteins, DARPP-32 (Ouimet et al., 1984) and ARPP21 (Ouimet et al., 1989). These proteins constitute a set of cAMP-regulated phosphoproteins which share a similar regional 


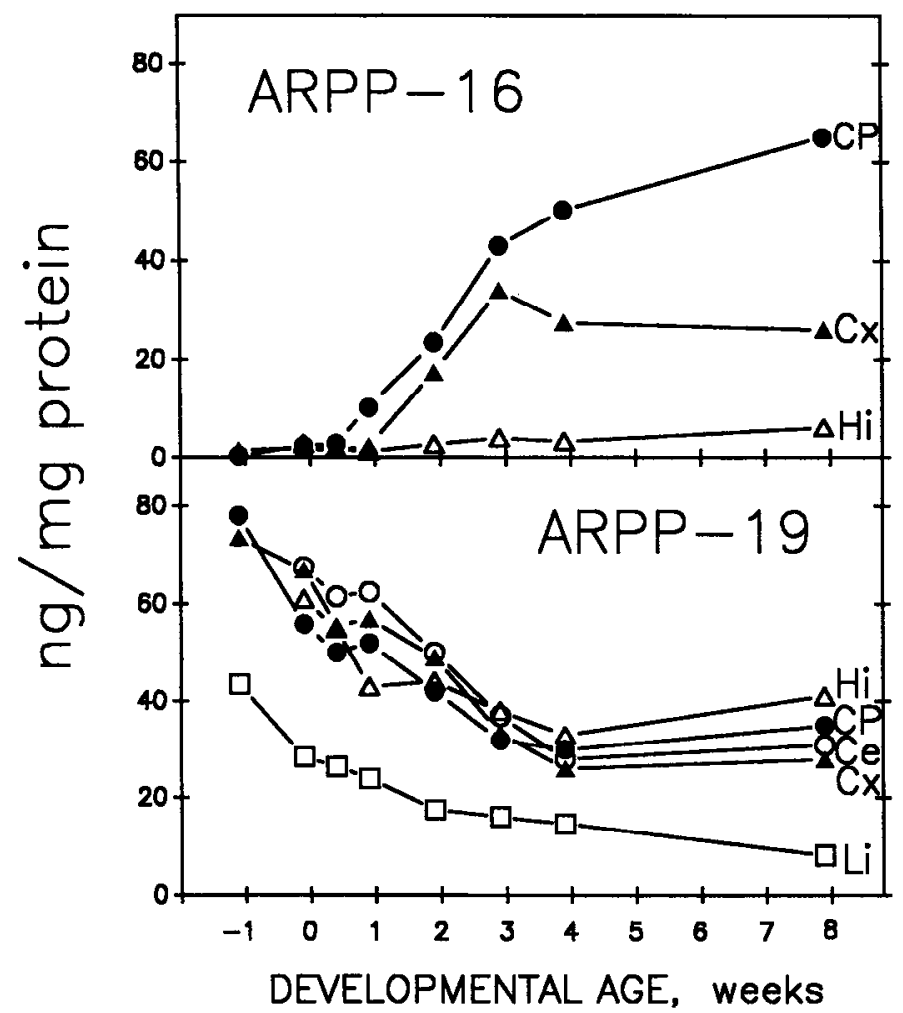

Figure 7. Development of ARPP-16 and ARPP-19 in mouse. Caudate putamen, cerebral cortex, hippocampus, cerebellum, and liver were dissected from mice at various ages from embryonic day 16 ( -1 week) to adult ( 8 weeks old). Tissue samples were homogenized in boiling SDS and the amounts of ARPP-16 and ARPP-19 were determined by immunoblotting, as described under Materials and Methods. Quantification was achieved by using known amounts of purified bovine ARPP16 and ARPP-19 on the same immunoblots. The data correspond to the mean of 2 independent experiments. Caudate putamen $(C P)$, cerebral cortex $(C x)$, hippocampus $(H i)$, cerebellum $(\mathrm{Ce})$, and liver $(\mathrm{Li})$.

distribution in brain, closely associated with that of the D1 dopamine receptor.

Some differences exist between the localization and the timing of the expression of DARPP-32 and ARPP-16. During development, ARPP-16 appeared in the early postnatal period, slightly later than DARPP-32 (Foster et al., 1987). In the cerebral cortex ARPP-16 was more widely distributed than DARPP-32. In contrast ARPP-16 was not detected in choroid plexus, which contain high levels of DARPP-32 (Hemmings and Greengard, 1986). Moreover, in the phylogenetic survey, ARPP-16 was not detected in various regions of turtle and pigeon brain, which contained DARPP-32 (Hemmings and Greengard, 1986; and J.-A.G., unpublished observations). These observations further emphasize the independence between the expression of ARPP16 and that of DARPP-32. Although ARPP-16 appears to be phylogenetically more recent than DARPP-32, the presence of ARPP-16 in mammals and in at least one species of bird, indicates that the expression of ARPP-16 is likely to have occurred before the divergence of birds' and mammals' ancestors.

In reaggregate striatal cultures, the phosphorylation state of ARPP-16 and ARPP-19 is regulated by CAMP and vasoactive intestinal peptide (Girault et al., 1988). In slices of adult rat striatum, 8-Br-cAMP and forskolin also increase the phosphorylation of both proteins (J.-A.G., unpublished observations). Therefore, it is expected that various neurotransmitters that raise cAMP levels in the cells where ARPP-16 and ARPP-19 are located will increase their state of phosphorylation, and further work is warranted to address that possibility. ARPP-16 and ARPP-19 being located in brain regions which contain VIP and VIP receptors (Fuxe et al., 1977; Sims et al., 1980; Theriault and Landis, 1987), it is likely that VIP regulates their state of phosphorylation in adult brain. However, there is no exclusive association between the distribution of ARPP-16 or ARPP-19 demonstrated in the present study and that of VIP (Fuxe et al., 1977; Sims et al., 1980). Since dopamine, acting on D1 receptors (Kebabian et al., 1972), raises cAMP levels in neurons which contain ARPP-16 and ARPP-19, it is also likely that dopamine regulates the state of phosphorylation of these 2 proteins, although this has not yet been shown experimentally. Moreover, the striking topographical association between ARPP-16 and dopamine D1 receptors suggests that this protein, as well as DARPP-32 (Hemmings et al., 1987), mediates specifically some of the postsynaptic actions of dopamine.

In conclusion, the results reported here show that 2 highly homologous cAMP-regulated phosphoproteins differ dramatically in their pattern of expression. While ARPP-19 appears to be ubiquitous and decreases with development, ARPP-16 is expressed only in a restricted set of brain neurons which receive an abundant dopaminergic innervation. ARPP-16 and ARPP19 should provide a unique model for addressing 2 sets of questions concerning the biology of dopaminoceptive neurons. First, determining the similarities and differences betwen the functions of ARPP-16 and those of ARPP-19 should give insights on the specific actions of dopamine acting through D1 receptors. Second, it will be of great interest to determine the mechanisms leading to the specific expression of ARPP-16 in a restricted set of central neurons.

\section{References}

Anthony, F. A., M. A. Winkler, H. H. Edwards, and W. Y. Cheung (1988) Quantitative subcellular localization of calmodulin-dependent phosphatase in chick forebrain. J. Neurosci. 8: 1245-1253.

Bjorklund, A., and O. Lindvall (1984) Dopamine-containing systems in the CNS. In Handbook of Chemical Neuroanatomy, Vol. 2, Part I, A. Bjorklund and T. Hökfelt, eds., pp. 55-122, Elsevier, Amsterdam.

Bond, R. W., K. R. Jansen, and D. A. Gottlieb (1988) Pattern of expression of glutamic acid decarboxylase mRNA in the developing rat brain. Proc. Natl. Acad. Sci. USA 85: 3231-3234.

Boyson, S. J., P. McGonigle, and P. B. Molinoff (1986) Quantitative autoradiographic localization of the D1 and D2 subtypes of dopamine receptors in rat brain. J. Neurosci. 6: 3177-3188.

Bradford, M. M. (1976) A rapid and sensitive method for the quantitation of microgram quantities of protein using the principle of protein dye binding. Anal. Biochem. 72: 248-254.

Dawson, T. M., D. R. Gehlert, R. T. McCabe, A. Barnett, and J. Wamsley (1986) D-1 dopamine receptors in the rat brain: A quantitative autoradiographic analysis. J. Neurosci. 6: 2352-2365.

Dubois, A., M. Savasta, O. Curet, and B. Scatton (1986) Autoradiographic distribution of the D1 agonist [3H]SKF 38393, in the rat brain and spinal cord. Comparison with the distribution of D2 dopamine receptors. Neuroscience 19: 125-137.

Dunkley, P. R., P. E. Jarvie, J. W. Heath, G. J. Kidd, and J. A. P. Rostas (1986) A rapid method for isolation of synaptosomes on Percoll gradients. Brain Res. 372: $115-129$.

Foster, G. A., M. Schultzberg, T. Hökfelt, M. Goldstein, H. C. Hemmings, Jr., C. C. Ouimet, S. I. Walaas, and P. Greengard (1987) Development of a dopamine- and cyclic adenosine $3^{\prime}: 5^{\prime}$-monophosphate-regulated phosphoprotein (DARPP-32) in the prenatal rat central nervous system, and its relationship to the arrival of presumptive dopaminergic innervation. J. Neurosci. 7: 1994-2018.

Fuxe, K., T. Hökfelt, S. I. Said, and V. Mutt (1977) Vasoactive intestinal polypeptide and the nervous system: Immunohistochemical evidence for localization in central and peripheral neurons, particu- 
larly intracortical neurons of the cerebral cortex. Neurosci. Lett. 5: 241-246.

Girault, J. A., I. A. Shalaby, N. L. Rosen, and P. Greengard (1988) Regulation by cAMP and vasoactive intestinal peptide of phosphorylation of specific proteins in striatal cells in culture. Proc. Natl. Acad. Sci. USA 85: 7790-7794.

Girault, J. A., F. S. Gorelick, and P. Greengard (1989a) Improving the quality of immunoblots by purification of antisera on a keratin affinity column. Anal. Biochem. 182: 193-196.

Girault, J. A., R. Raisman-Vozari, Y. Agid, and P. Greengard (1989b) Striatal phosphoproteins in Parkinson's disease and progressive supranuclear palsy. Proc. Natl. Acad. Sci. USA 86: 2493-2497.

Graybiel, A. M., and C. W. Ragsdale (1983) Biochemical anatomy of the striatum. In Chemical Neuroanatomy, P. C. Emson, ed., pp. 427503, Raven, New York.

Hemmings, H. C., Jr., and P. Greengard (1986) DARPP-32, a dopamine- and adenosine $3^{\prime}: 5^{\prime}$-monophosphate-regulated phosphoprotein: Regional, tissue, and phylogenetic distribution. J. Neurosci. 6 : 1469-1481.

Hemmings, H. C., Jr., S. I. Walaas, C. C. Ouimet, and P. Greengard (1987) Dopaminergic regulation of protein phosphorylation in the striatum: DARPP-32. Trends Neurosci. 10: 377-383.

Hsu, S., I. Raine, and H. Fanger (1981) Use of avidin-biotin-peroxidase complex $(A B C)$ in immunoperoxidase techniques: $A$ comparison between $\mathrm{ABC}$ and unlabelled antibody (PAP) procedures. J. Histochem. Cytochem. 29: 577-580.

Jacobson, K. D., I. Virag, and J. H. P. Skene (1986) A protein associated with axon growth, GAP43, is widely distributed and developmentally regulated in rat CNS. J. Neurosci. 6: 1843-1855.

Kebabian, J. W., G. L. Petzold, and P. Greengard (1972) Dopaminesensitive adenylate cyclase in caudate nucleus of rat brain, and its similarity to the "dopamine receptor." Proc. Natl. Acad. Sci. USA 69: 2145-2149

Kessler, J. A. (1986) Differential regulation of cholinergic and peptidergic development in the rat striatum in culture. Dev. Biol. 113: 7789.

Laemmli, U. K. (1970) Cleavage of structural proteins during the assembly of the head of bacteriophage T4. Nature 227: 680-685.

Lohmann, S. M., T. Ueda, and P. Greengard (1978) Ontogeny of synaptic phosphoproteins in brain. Proc. Natl. Acad. Sci. USA 75 4037-4041.

Matus, A. (1988) Microtubule-associated proteins: Their potential role in determining neuronal morphology. Annu. Rev. Neurosci. 11: 2944.

Moore, R. Y., and M. E. Bernstein (1989) Synaptogenesis in the rat suprachiasmatic nucleus demonstrated by electron microscopy and synapsin I immunoreactivity. J. Neurosci. 9: 2151-2162.

Nairn, A. C., H. C. Hemmings, Jr., and P. Greengard (1985) Protein kinases in the brain. Annu. Rev. Biochem. 54: 931-976.

Nestler, E. J., and P. Greengard (1983) Protein phosphorylation in the brain. Nature 305: 583-588.

Ouimet, C. C., P. E. Miller, H. C. Hemmings, Jr., S. I. Walaas, and P.
Greengard (1984) DARPP-32, a dopamine- and adenosine 3':5'monophosphate-regulated phosphoprotein enriched in dopamine-innervated brain regions. III. Immunocytochemical localization. J. Neurosci. 4: 111-124.

Ouimet, C. C., H. C. Hemmings, Jr., and P. Greengard (1989) ARPP21 , a cyclic AMP-regulated phosphoprotein enriched in dopamineinnervated brain regions. II. Immunocytochemical localization in rat brain. J. Neurosci. 9: 865-875.

Paxinos, G., and C. Watson (1986) The Rat Brain in Stereotaxic Coordinates, Academic, Sydney.

Quik, M., P. C. Emson, and E. Joyce (1979) Dissociation between the presynaptic dopamine-sensitive adenylate cyclase and $(3 \mathrm{H})$ spiperone binding sites in rat substantia nigra. Brain Kes. 167: 355-365.

Savasta, M., A. Dubois, and B. Scatton (1986) Autoradiographic localization of D1 receptors in the rat brain with $[3 \mathrm{H}] \mathrm{SCH} 23390$. Brain Res. 375: 291-301.

Schoenfeld, T. A., L. McKerracher, R. Obar, and R. B. Vallee (1989) MAP $1 \mathrm{~A}$ and MAP $1 \mathrm{~B}$ are structurally related microtubule associated proteins with distinct developmental patterns in the CNS. J. Neurosci. 9: $1712-1730$.

Schwarcz, R., W. O. Whetsell, and R. M. Mangano (1983) Quinolinic acid: An endogenous metabolite that produces axon-sparing lesions in rat brain. Science 219:316-318.

Sims, K. B., D. L. Hofman, S. I. Said, and E. A. Zimmerman (1980) Vasoactive intestinal polypeptide (VIP) in mouse and rat brain: An immunocytochemical study. Brain Res. 186: 165-183.

Smith, P. K., R. I. Krohn, G. T. Hermanson, A. K. Mallia, F. H. Gartner, M. D. Provenzano, E. K. Fujimoto, N. M. Goeke, B. J. Olson, and D. C. Klenk (1985) Measurement of protein using bicinchoninic acid. Anal. Biochem. 150: 76-85.

Theriault, E., and M. D. Landis (1987) Morphology of striatal neurons containing VIP-like immunoreactivity. I. Comp. Neurol. 256: 1-13.

Towbin, H., T. Staehlin, and J. Gordon (1979) Electrophoretic transfer of proteins from polyacrylamide gels to nitrocellulose sheets: Procedure and some applications. Proc. Natl. Acad. Sci. USA 76: 43504354.

Walaas, S. I., and P. Greengard (1984) DARPP-32, a dopamine- and adenosine $3^{\prime}: 5^{\prime}$-monophosphate-regulated phosphoprotein enriched in dopamine-innervated brain regions. I. Regional and cellular distribution in the rat brain. J. Neurosci. 4: 84-98.

Walaas, S. I., A. C. Nairn, and P. Greengard (1983a) Regional distribution of calcium- and cyclic adenosine $3^{\prime}: 5^{\prime}$-monophosphate-regulated protein phosphorylation systems in mammalian brain. II. Soluble systems. J. Neurosci. 3: 302-311.

Walaas, S. I. A. C. Nairn, and P. Greengard (1983b) Regional distribution of calcium- and cyclic adenosine $3^{\prime}: 5^{\prime}$-monophosphate-regulated protein phosphorylation systems in mammalian brain. I. Particulate systems. J. Neurosci. 3: 291-301.

Yamamoto, K. K., G. A. Gonzalez, W. Biggs III, and M. R. Montminy (1988) Phosphorylation-induced binding and transcriptional efficacy of nuclear factor CREB. Nature 334: 494-498. 